\title{
Optimized inorganic carbon regime for enhanced growth and lipid accumulation in Chlorella vulgaris
}

Egan J Lohman ${ }^{1 \dagger}$, Robert D Gardner ${ }^{1,2+}$, Todd Pedersen ${ }^{1}$, Brent M Peyton ${ }^{1}$, Keith E Cooksey ${ }^{3}$ and Robin Gerlach ${ }^{1 *}$

\begin{abstract}
Background: Large-scale algal biofuel production has been limited, among other factors, by the availability of inorganic carbon in the culture medium at concentrations higher than achievable with atmospheric $\mathrm{CO}_{2}$. Life cycle analyses have concluded that costs associated with supplying $\mathrm{CO}_{2}$ to algal cultures are significant contributors to the overall energy consumption.
\end{abstract}

Results: A two-phase optimal growth and lipid accumulation scenario is presented, which (1) enhances the growth rate and (2) the triacylglyceride (TAG) accumulation rate in the oleaginous Chlorophyte Chlorella vulgaris strain UTEX 395 , by growing the organism in the presence of low concentrations of $\mathrm{NaHCO}_{3}(5 \mathrm{mM})$ and controlling the $\mathrm{pH}$ of the system with a periodic gas sparge of $5 \% \mathrm{CO}_{2}(\mathrm{~V} / \mathrm{V})$. Once cultures reached the desired cell densities, which can be "fine-tuned" based on initial nutrient concentrations, cultures were switched to a lipid accumulation metabolism through the addition of $50 \mathrm{mM} \mathrm{NaHCO}_{3}$. This two-phase approach increased the specific growth rate of $\mathrm{C}$. vulgaris by $69 \%$ compared to cultures sparged continuously with $5 \% \mathrm{CO}_{2}(\mathrm{~V} / \mathrm{V})$; further, biomass productivity $\left(\mathrm{g} \mathrm{L}^{-1}\right.$ day $^{-1}$ ) was increased by $27 \%$. Total biodiesel potential [assessed as total fatty acid methyl ester (FAME) produced] was increased from 53.3 to $61 \%$ (FAME biomass ${ }^{-1}$ ) under the optimized conditions; biodiesel productivity (g FAME L ${ }^{-1}$ day $^{-1}$ ) was increased by $7.7 \%$. A bicarbonate salt screen revealed that American Chemical Society (ACS) and industrial grade $\mathrm{NaHCO}_{3}$ induced the highest TAG accumulation $(\% \mathrm{~W} / \mathrm{W})$, whereas $\mathrm{Na}_{2} \mathrm{CO}_{3}$ did not induce significant TAG accumulation. $\mathrm{NH}_{4} \mathrm{HCO}_{3}$ had a negative effect on cell health presumably due to ammonia toxicity. The raw, unrefined form of trona, $\mathrm{NaHCO}_{3} \cdot \mathrm{Na}_{2} \mathrm{CO}_{3}$ (sodium sesquicarbonate) induced TAG accumulation, albeit to a slightly lower extent than the more refined forms of sodium bicarbonate.

Conclusions: The strategic addition of sodium bicarbonate was found to enhance growth and lipid accumulation rates in cultures of $C$. vulgaris, when compared to traditional culturing strategies, which rely on continuously sparging algal cultures with elevated concentrations of $\mathrm{CO}_{2(\mathrm{~g})}$. This work presents a two-phased, improved photoautotrophic growth and lipid accumulation approach, which may result in an overall increase in algal biofuel productivity.

Keywords: Triacylglycerol (TAG), Microalgae, Biodiesel, Fatty acid methyl ester (FAME), Chlorella vulgaris, Bicarbonate, $\mathrm{CO}_{2}$, Nitrogen limitation

\footnotetext{
* Correspondence: robin_g@coe.montana.edu

${ }^{\dagger}$ Equal contributors

${ }^{1}$ Center for Biofilm Engineering and Department of Chemical and Biological

Engineering, Montana State University, Bozeman, MT 59717, USA

Full list of author information is available at the end of the article
}

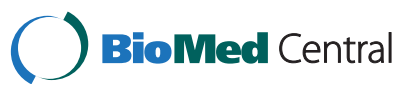




\section{Background}

The extraction and refinement of petroleum as a natural resource for fuel and specialty chemicals has enabled human innovation and led to unprecedented technological growth in industrialized nations; however, these technological advancements are not without cost. The current rate of producing enough crude petroleum to satisfy global demand has led to political, economic, and environmental controversy [1]. The US alone currently consumes over 18 million barrels of crude oil each day, with a significant percentage being imported from foreign sources [2]. Additionally, atmospheric concentrations of carbon dioxide have risen drastically due to the increasing combustion of fossil fuels [3, 4]. Carbon dioxide is one of the most prevalent greenhouse gases responsible for global climate change and ocean acidification. Industrial processes and the transportation sector currently contribute more than 29 billion tonnes of carbon dioxide to the atmosphere each year [3]. This is more than $400 \times$ the estimated rate of global carbon fixation by primary biota [5].

Renewable sources of energy rich, biologically produced feed stocks are needed to offset this trend. Corn, soybean, and sugar cane are the current primary sources for bioethanol and biodiesel; however these crops compete for arable land needed to produce food [6]. Algal-derived biofuels, especially biodiesel, have received increased attention in recent decades as a potential renewable energy resource [1, 7-9]. Based on life cycle analyses and conservative estimates of biodiesel yields, it has been projected that less than $5 \%$ of currently available arable land would be required to displace $50 \%$ of fossil fuel consumption in the USA [10]. This estimate is even more appealing when considering the fact that microalgae do not require arable land as they are not a conventional crop; rather, algal ponds require flat terrain, appropriate temperature, abundant sunlight, water, and nutrients. It should be noted, however, that non-arable land use for large-scale cultivation of microalgae will certainly impact the environment and these impacts should be evaluated.

Next to sunlight and water, the most prerequisite resource is inorganic carbon, which is necessary for photoautotrophic cell growth as well as lipid synthesis. Biodiesel, defined as fatty acid methyl ester (FAME), has similar chemical properties to traditional diesel fuel, and can be produced from energy-rich storage compounds such as triacylglycerols (TAGs), which can be synthesized by microalgae in relatively high abundance [10]. TAGs are comprised of long chain hydrocarbons (fatty acids) and a glycerol backbone, and a fundamental requirement for their synthesis is inorganic carbon availability to the organism. To realize commercial scale development of algal-derived biofuels, optimized processes for the delivery and biological uptake of inorganic carbon are important to increase productivity. This study focuses on the strategic use of bicarbonate salts to provide the necessary amounts of dissolved inorganic carbon (DIC) for increased growth and lipid production by Chlorella vulgaris sp. strain UTEX 395 . This study demonstrates an optimized two-phase growth and lipid accumulation strategy to increase the specific growth rate and induce lipid accumulation in C. vulgaris. The results presented offer a promising strategy for optimizing productivity and reducing resource costs.

\section{Experimental design and rationale}

Although microalgae will grow under atmospheric concentrations of inorganic $\mathrm{CO}_{2}(\sim 400 \mathrm{ppm})$, improved biomass yields can be achieved by supplementing with additional inorganic carbon. It is often cited that this additional carbon source could come from industrial waste such as power plant flue gas $[9,11]$. Unfortunately, studies have suggested that this process may be economically cost prohibitive [12-14]. Moreover, a recent life cycle analysis has shown that due to the inefficiency of aerating open algal ponds with $\mathrm{CO}_{2}$ gas, there may not be enough $\mathrm{CO}_{2}$ produced from waste streams required for large scale algal biofuel production [14]. This is, in part, because the kinetics of $\mathrm{CO}_{2}$ dissolution are slow enough that in open ponds of shallow depths, the majority of $\mathrm{CO}_{2}$ gas sparged into the pond can escape into the atmosphere $[13,15,16]$. The efficiency of $\mathrm{CO}_{2}$ transfer into aqueous solutions will, among other factors, depend on the deviation of medium conditions from equilibrium with the sparged gas (and the atmosphere), the contact time (e.g., depth of the water column), and the contact surface area (e.g., bubble size) [16-19]. Solutions with high non-carbonate alkalinity, e.g., solutions with high hydroxyl ion concentrations (high $\mathrm{pH}$ ) will have a higher capacity to absorb $\mathrm{CO}_{2}$. In these solutions, the hydroxyl-based alkalinity will be converted into carbonate and bicarbonate alkalinity [17]. The ratio of the three different DIC species [dissolved carbon dioxide $\left(\mathrm{CO}_{2(\mathrm{aq})}\right)$, bicarbonate $\left(\mathrm{HCO}_{3}^{-}\right)$, and carbonate $\left.\left(\mathrm{CO}_{3}^{2-}\right)\right]$ is determined by the $\mathrm{pH}$ of a system, whether in equilibrium with the atmosphere or not $[17$, 19-21].

While research has suggested that the preferential species for microalgae is $\mathrm{CO}_{2(\mathrm{aq})}$ [22], at the optimal $\mathrm{pH}$ range for growth ( $\mathrm{pH} 7-9$ ), the predominant species is bicarbonate. Many microalgae have developed $\mathrm{CO}_{2}$ concentrating mechanisms (CCMs) which allow them to actively transport the bicarbonate anion $\left(\mathrm{HCO}_{3}^{-}\right)$to $\mathrm{RuBisCO}$ and thus utilize both carbon dioxide and bicarbonate as carbon source [15, 23-31]. When $\mathrm{HCO}_{3}^{-}$is utilized, hydroxyl ions are released $\left(\mathrm{HCO}_{3}^{-} \rightarrow \mathrm{CO}_{2}+\mathrm{OH}^{-}\right)$. This process results in the production of hydroxyl-based alkalinity from carbonate alkalinity effectively increasing the driving force for 
additional $\mathrm{CO}_{2}$ dissolution into the medium as outlined above [17, 32].

Additionally, our previous research has revealed that the timely addition of bicarbonate to microalgae cultures induces a significant increase in TAG accumulation [33]. This "bicarbonate trigger" has been tested and optimized on various species, including Chlorophytes and diatoms [33-37]. In this study, it is compared how various bicarbonate salts induce TAG accumulation, and a two-phase, enhanced growth and lipid accumulation scenario is presented for cultures of C. vulgaris. By supplementing cultures with low doses of bicarbonate to first enhance the specific growth rate and secondly by adding elevated concentrations of bicarbonate in concert with medium nitrogen depletion, both growth and lipid accumulation rates were significantly increased. The description of the results and discussion is separated into two parts. The first part details the results of using various bicarbonate salts to induce lipid accumulation, while the second part presents an optimized growth and lipid accumulation scenario.

\section{Results and discussion}

\section{Part 1: carbonate salt screen for lipid production}

To the best of our knowledge, only ACS grade $\mathrm{NaHCO}_{3}$ has been used to induce TAG accumulation in microalgae [33-35, 38]. From an industrial cost perspective, a less refined and hence less expensive source of inorganic bicarbonate will be preferable. Five different bicarbonate salts and one carbonate salt (Table 1) were evaluated regarding their potential to induce TAG accumulation relative to ambient air sparged cultures using C. vulgaris. Briefly, batch cultures of $C$. vulgaris were grown in Bold's basal medium until just prior to nitrogen depletion, at which time the cultures were pooled, harvested by centrifugation, and transferred into medium supplemented with inorganic carbon and deplete of any nitrogen source. Seven experimental conditions were designed to compare extractable lipid accumulation as monitored by gas chromatography-flame ionization detection (GC-FID) and total biodiesel potential via gas chromatographymass spectroscopy (GC-MS). Extractable lipids are defined here as intracellular lipids such as TAGs, free fatty acids (FFAs), monoacylglycerides (MAGs), or diacylglycerides (DAGs), which can be liberated from lysed cells using non-polar solvents. Our previous work has shown that GC-FID analysis can be effectively used for the characterization of extractable lipids from microalgae cultures [39]. Total biodiesel potential is defined here as the mass of all fatty acids (polar and non-polar), which are quantified by transesterification into FAMEs. The values are usually expressed in weight FAME per weight biomass and are assessed based on carbon chain length and saturation via GC-MS [39]. FAMEs can originate from TAG, DAG, MAG, FFA as well as membrane and glycolipids $[39,40]$.

Six experimental groups in triplicate received the following sources of dissolved inorganic carbon (DIC, 50 mM C final concentration): (1) ACS grade $\mathrm{NaHCO}_{3}$, (2) industrial grade $\mathrm{NaHCO}_{3}$, (3) $\mathrm{KHCO}_{3}$, (4) $\mathrm{NH}_{4} \mathrm{HCO}_{3}$, (5) $\mathrm{Na}_{2} \mathrm{CO}_{3}$, and (6) $\mathrm{NaHCO}_{3} \cdot \mathrm{Na}_{2} \mathrm{CO}_{3}$. These treatments were compared with each other and a control, which received no additional inorganic carbon. Table 1 presents culture characteristics for each treatment at the conclusion of the experiment. As expected based on our

Table 1 C. vulgaris culture characteristics during nitrogen limited growth when supplemented with various bicarbonate salts

\begin{tabular}{|c|c|c|c|c|c|c|c|}
\hline Treatment & $\begin{array}{l}\text { Cell concentration } \\
\left(\times 10^{7} \text { cells } \mathrm{mL}^{-1}\right)\end{array}$ & $\begin{array}{l}\text { Cell } \\
\text { doublings }^{\mathrm{a}}\end{array}$ & $\begin{array}{l}\text { Dry weight } \\
\left(\mathrm{g} \mathrm{L}^{-1} ; \mathrm{DCW}\right)^{\mathrm{b}}\end{array}$ & $\begin{array}{l}\text { Endpoint } \\
\mathrm{pH}\end{array}$ & $\begin{array}{l}\text { Total } \\
\text { chlorophyll } \\
\left(\mathrm{mg} \mathrm{L}^{-1}\right)\end{array}$ & $\begin{array}{l}\text { Total chlorophyll per } \\
\text { cell (pg) }\end{array}$ & $\begin{array}{l}\text { Dry weight per } \\
\text { cell (ng) }\end{array}$ \\
\hline $0 \mathrm{mM} \mathrm{HCO}_{3}^{-}$ & $3.48 \pm 0.17$ & $2.47 \pm 0.23$ & $0.37 \pm 0.03$ & $8.08 \pm 0.07$ & $1.82 \pm 0.08$ & $0.052 \pm 0.004$ & $0.011 \pm 0.001$ \\
\hline $\begin{array}{l}50 \mathrm{mM} \text { ACS grade } \\
\mathrm{NaHCO}_{3}\end{array}$ & $2.15 \pm 0.17^{*}$ & $\begin{array}{l}1.35 \pm \\
0.19^{*}\end{array}$ & $0.58 \pm 0.06^{* *}$ & $9.82 \pm 0.03^{* *}$ & $2.00 \pm 0.34$ & $0.093 \pm 0.011^{* *}$ & $0.027 \pm 0.001^{* *}$ \\
\hline $\begin{array}{l}50 \mathrm{mM} \text { industrial grade } \\
\mathrm{NaHCO}_{3}\end{array}$ & $1.78 \pm 0.13^{*}$ & $\begin{array}{l}0.64 \pm \\
0.40^{*}\end{array}$ & $0.60 \pm 0.02^{* *}$ & $9.82 \pm 0.06^{* *}$ & $1.72 \pm 0.18$ & $0.097 \pm 0.016^{* *}$ & $0.034 \pm 0.003^{* *}$ \\
\hline $50 \mathrm{mM} \mathrm{KHCO}_{3}$ & $1.56 \pm 0.13^{*}$ & $\begin{array}{l}0.88 \pm \\
0.27^{*}\end{array}$ & $0.54 \pm 0.03^{* *}$ & $9.77 \pm 0.03^{* *}$ & $2.01 \pm 0.21$ & $0.129 \pm 0.013^{* *}$ & $0.035 \pm 0.003^{* *}$ \\
\hline $50 \mathrm{mM} \mathrm{NH}_{4} \mathrm{HCO}_{3}$ & $0.62 \pm 0.04^{*}$ & $\begin{array}{l}-0.25 \pm \\
0.47^{*}\end{array}$ & $0.15 \pm 0.04^{*}$ & $9.31 \pm 0.05^{* *}$ & $0.31 \pm 0.17^{*}$ & $0.031 \pm 0.014$ & $0.016 \pm 0.005$ \\
\hline $50 \mathrm{mM} \mathrm{Na}_{2} \mathrm{CO}_{3}$ & $1.21 \pm 0.22^{*}$ & $\begin{array}{l}0.83 \pm \\
0.15^{*}\end{array}$ & $0.35 \pm 0.01$ & $9.98 \pm 0.02^{* *}$ & $1.37 \pm 0.15^{*}$ & $0.115 \pm 0.024^{* *}$ & $0.029 \pm 0.006^{* *}$ \\
\hline $\begin{array}{l}25 \mathrm{mM} \\
\mathrm{NaHCO}_{3} \cdot \mathrm{Na}_{2} \mathrm{CO}_{3}\end{array}$ & $1.21 \pm 0.16^{*}$ & $\begin{array}{l}0.38 \pm \\
0.42^{*}\end{array}$ & $0.49 \pm 0.04^{* *}$ & $9.83 \pm 0.03^{* *}$ & $1.77 \pm 0.22$ & $0.149 \pm 0.036^{* *}$ & $0.041 \pm 0.008^{* *}$ \\
\hline
\end{tabular}

Values are reported for the completion of the experiment (5.75 days) $(n=3)$

${ }^{*} p$ value $<0.05$ as determined by a two-tailed $t$ test, statistically significantly lower [difference between treatment and control group $\left(0 \mathrm{mM} \mathrm{HCO}_{3}^{-}\right)$]

${ }^{* *} p$ value $<0.05$ as determined by a two-tailed $t$ test, statistically significantly higher [difference between treatment and control group ( 0 mM $\mathrm{HCO}_{3}^{-}$)]

${ }^{a}$ Cell doublings are calculated as $n=\log _{2}\left(C_{f} / C_{i}\right)$; where $n$ is the number of cell doublings and $C_{f}$ and $C_{i}$ are final and initial cell concentrations, respectively

${ }^{b}$ Dry cell weight (DCW) determined gravimetrically with lyophilized biomass 
previous work [33, 34, 41], the cultures that did not receive any bicarbonate or carbonate increased in cell concentration from $6.3 \times 10^{6}$ cells $\mathrm{mL}^{-1}$ until reaching stationary growth at $3.5 \times 10^{7}$ cells $\mathrm{mL}^{-1}$ (Table 1 ), whereas cultures supplemented with $50 \mathrm{mM}$ DIC (as carbonate or bicarbonate) did not increase as much, remained stagnant, or even decreased in cell numbers $\left(\mathrm{NH}_{4} \mathrm{HCO}_{3}\right)$. However, even though cell numbers did not increase as much in bicarbonate supplemented treatments, cell dry weights in all bicarbonate supplemented cultures, except the $\mathrm{NH}_{4} \mathrm{HCO}_{3}$ supplemented treatment, increased. This resulted in higher dry weights per cell in the bicarbonate- and carbonate-amended treatments compared to the control treatments (Table 1). Conversely, analysis of the concentration of chlorophyll indicates no statistical difference between the control treatments and those that received bicarbonate additions, with exception of those that received $\mathrm{NH}_{4} \mathrm{HCO}_{3}$ and the treatments which received carbonate. When normalized to the cell number, there was significantly more chlorophyll per cell in all salt amendments with exception to those that received $\mathrm{NH}_{4} \mathrm{HCO}_{3}$ (Table 1). Again, this is due to the delay or arresting of the cellular division, and this phenomenon has been well documented and is believed to be the result of a fundamental metabolic shift from growth metabolism to lipid accumulation metabolism after bicarbonate addition [33-35].

Figure 1 presents the extractable lipids (FFA, MAG, DAG, TAG) and in situ transesterified FAMEs for each culture after maximum TAG accumulation (5.75 days of $\mathrm{N}$-limited culturing) [39]. Cultures supplemented with $50 \mathrm{mM}$ ACS or industrial grade bicarbonate accumulated the most TAG $(22.9 \pm 1.5$ and $24.3 \pm 0.7 \% w / w$, respectively), as compared to the cultures which did not receive any additional DIC $(13.3 \pm 3.4 \% w / w)$. Cultures supplemented with $50 \mathrm{mM} \mathrm{KHCO}$ or $25 \mathrm{mM} \mathrm{Na}_{2} \mathrm{CO}_{3}$.$\mathrm{NaHCO}_{3}$ also accumulated a significant amount of TAG $(17.7 \pm 1.7$ and $19.5 \pm 0.797 \% w / w$, respectively), albeit less than cultures supplemented with ACS or industrial grade $\mathrm{NaHCO}_{3}$ (Fig. 1). Sodium sesquicarbonate is the raw material (i.e., trona) used for the production of the more refined grades of carbonates/bicarbonates. Trona typically contains high concentrations of silicates and other compounds and is likely one of the least expensive forms of bicarbonate available.

Cultures treated with $50 \mathrm{mM} \mathrm{NH} \mathrm{mCO}_{3}$ did not accumulate TAG (data not shown), declined in cell concentration after 2 days of incubation (Additional file 1) and reached cell concentrations and cell dry weights significantly lower than all the other cultures at the end of the experiment (Table 1). The final pH of the $\mathrm{NH}_{4} \mathrm{HCO}_{3}$ amended system was approximately 9.3 (Fig. 2, Table 1), which is equal to the $\mathrm{pKa}$ for the $\mathrm{NH}_{4}^{+} / \mathrm{NH}_{3}$ equilibrium, indicating that high concentrations of $\mathrm{NH}_{3}$ were present.

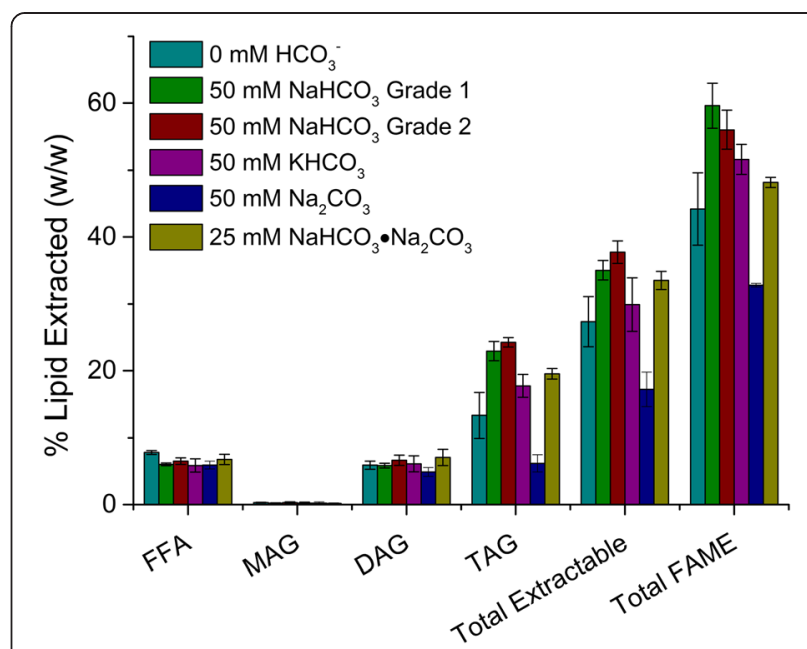

Fig. 1 Extractable lipid class and FAME profiles for cultures of $C$. vulgaris re-suspended into medium depleted of nitrogen and supplemented with various bicarbonate salts. Final concentrations of bicarbonate salts per experimental condition: $0 \mathrm{mM} \mathrm{HCO}_{3}^{-}$(control), $50 \mathrm{mM}$ ACS grade $\mathrm{NaHCO}_{3}$ (grade 1), $50 \mathrm{mM}$ industrial grade $\mathrm{NaHCO}_{3}$ (grade 2), $50 \mathrm{mM} \mathrm{KHCO}, 50 \mathrm{mM} \mathrm{Na}_{2} \mathrm{CO}_{3}$, and $25 \mathrm{mM}$ $\mathrm{NaHCO}_{3} \cdot \mathrm{Na}_{2} \mathrm{CO}_{3}$ (25 mM of sesquicarbonate was used to provide equimolar carbon). Values are reported for the completion of the experiment $(n=3)$. All values expressed as weight percent (\% weight extractable lipid or weight FAME/weight biomass)

The decline in cell concentration is presumably due to the toxic effects of ammonia, which has been shown previously to inhibit photosynthesis in microalgal cultures [42].

Finally, cultures supplemented with $50 \mathrm{mM} \mathrm{Na} \mathrm{CO}_{3}$ accumulated a significantly lower percentage of TAG $(6.2 \pm 1.3 \% w / w)$ compared to all other treatments (Fig. 1, Table 2). There are no known metabolic pathways through which $C$. vulgaris can assimilate $\mathrm{CO}_{3}^{2-}$ into biomass and at the initial pH 11.4 (Fig. 2) virtually all of the dissolved inorganic carbon would have been present as carbonate (the pKa for the $\mathrm{HCO}_{3}^{-} / \mathrm{CO}_{3}^{2-}$ equilibrium is approximately at $\mathrm{pH} 10.3$ ). However, throughout the experiment, the $\mathrm{pH}$ continuously decreased and reached a final pH of 9.98 (Fig. 2, Table 1); thereby, speciation was shifted to predominantly bicarbonate which became bioavailable to the alga. It is presumed that the higher sodium concentration in the $\mathrm{CO}_{3}^{2-}$ amended systems may also have influenced lipid metabolism in C. vulgaris. However, Gardner et al. (2013) showed that the addition of up to $50 \mathrm{mM}$ sodium ions did not have a negative effect on the lipid accumulation activity of a Scenedesmus sp. [41]. This effect will have to be investigated further in the future for $C$. vulgaris.

Free fatty acid, MAG and DAG contents were statistically the same in all treatments $(6.5 \pm 0.3,0.24 \pm 0.06$, $6.1 \pm 0.34 \% w / w$, respectively, Fig. 1); thus, the total extractable lipid content (sum of FFA, MAG, DAG, and 


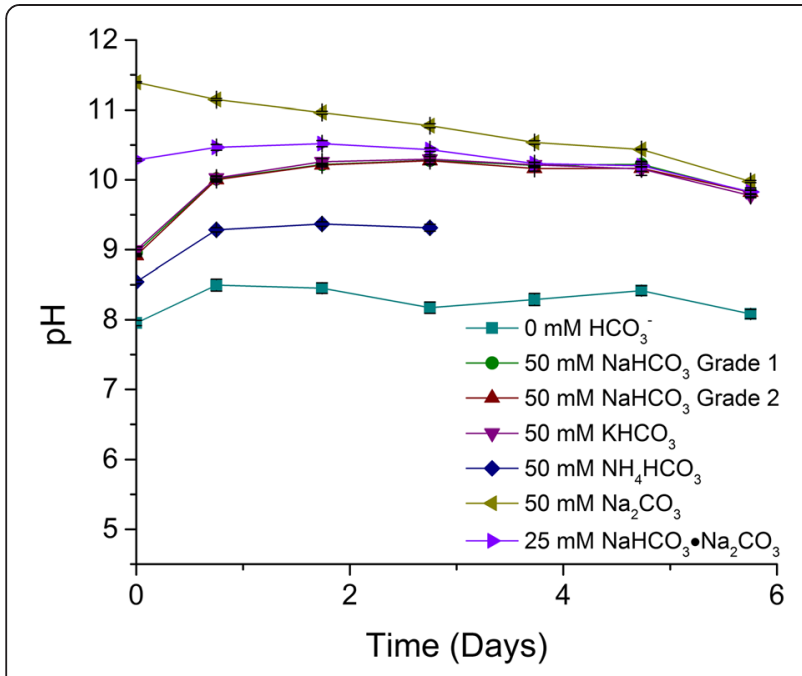

Fig. 2 pH for cultures of C. vulgaris re-suspended into medium depleted of nitrogen and supplemented with various bicarbonate salts. Final concentrations of bicarbonate salts per experimental condition: $0 \mathrm{mM} \mathrm{HCO}_{3}^{-}$(control), $50 \mathrm{mM} \mathrm{ACS}$ grade $\mathrm{NaHCO}_{3}$ (grade 1), $50 \mathrm{mM}$ industrial grade $\mathrm{NaHCO}_{3}$ (grade 2), $50 \mathrm{mM} \mathrm{KHCO}_{3}, 50 \mathrm{mM}$ $\mathrm{NH}_{4} \mathrm{HCO}_{3}, 50 \mathrm{mM} \mathrm{Na} \mathrm{CO}_{3}$, and $25 \mathrm{mM} \mathrm{NaHCO} \cdot \mathrm{Na}_{2} \mathrm{CO}_{3}(25 \mathrm{mM}$ of sesquicarbonate was used to provide equimolar carbon) $(n=3)$

TAG) for each culture followed the same trend as the TAG content per cell. Total biodiesel potential (as \% $w / w$ FAME) and potential biodiesel productivity (as $g$ $\mathrm{L}^{-1}$ day $^{-1}$ FAME) [43] mirrored the trend of the TAG contents. Cultures treated with $50 \mathrm{mM}$ ACS and industrial grade $\mathrm{NaHCO}_{3}$ accumulated the most FAME at $59.6 \pm 3.3$ and $56.0 \pm 2.9 \% w / w$ and had the highest potential biodiesel productivity with $0.061 \pm 0.008$ and $0.058 \pm 0.001 \mathrm{~g} \mathrm{~L}^{-1} \mathrm{day}^{-1}$, respectively (Table 2). FAME profiles are further expanded upon in Table 2, which presents a number of FAMEs separated by carbon chain length and saturation. Overall, C. vulgaris primarily synthesized $\mathrm{C}_{18}$ fatty acids, specifically monounsaturated $\mathrm{C}_{18}$ as reported previously [38, 39, 44]. The cultures which did not receive additional inorganic carbon, however, produced only approximately half (16.8 \pm 3 $\% w / w)$ as much $\mathrm{C} 18: 1$ fatty acids compared to the treatment which received $50 \mathrm{mM}$ ACS grade $\mathrm{NaHCO}_{3}(31.8 \pm$ $1.7 \% w / w)$ or the industrial grade $\mathrm{NaHCO}_{3}(30.1 \pm 1.4 \%$ $w / w)$. This indicates that a large fraction of the C18:1fatty acids were synthesized as a result of elevated concentrations of DIC (Table 2). Interestingly, the cultures which did not receive additional inorganic carbon produced equivalent concentrations of fully saturated C16:0 fatty acids and poly-unsaturated C18:3 fatty acids compared to treatments which received sodium bicarbonate (Table 2).

These results are consistent with previous reports describing changes in the fatty acid profiles of C. vulgaris UTEX 395 when cultured under nitrogen deprivation [44, 45]. For example, Guarnieri et al. (2011) reported a 9-fold increase in C18:1 fatty acid when UTEX 395 was cultured in nitrogen-free medium. Here, the addition of sodium bicarbonate resulted in a 2 -fold increase in C18:1 fatty acid content based on cell dry weight over the bicarbonate-free control, which suggests that bicarbonate can enhance fatty acid synthesis in concert with nitrogen depletion.

The results from evaluating the effect of (bi)carbonate salts on lipid accumulation provided evidence that the timely addition of bicarbonate, when coupled with nitrogen depletion, can induce significant lipid accumulation and promote the preferential production of C18:1 fatty acid in C. vulgaris. Not only was the lipid content per biomass (biodiesel potential in $\% w / w$ ) higher in the bicarbonate triggered cells, but due to the higher dry weight for the bicarbonate triggered cells, the potential biodiesel productivity (g FAME $\mathrm{L}^{-1} \mathrm{~d}^{-1}$ ) was also higher in the bicarbonate-triggered cultures. However, as noted, the

Table 2 FAME profiles of C. vulgaris when supplemented with various bicarbonate salts just prior to nitrogen depletion

\begin{tabular}{|c|c|c|c|c|c|c|c|c|c|}
\hline Treatment & C16:0 & C16:1 & C18:0 & C18:1 & C18:2 & C18:3 & Other $^{a}$ & $\begin{array}{l}\text { Total biodiesel } \\
\text { potential }(\%)^{b}\end{array}$ & $\begin{array}{l}\text { Potential biodiesel } \\
\text { productivity } \\
\left(\mathrm{g} \mathrm{L}^{-1} \text { day }^{-1}\right)^{\mathrm{b}}\end{array}$ \\
\hline $0 \mathrm{mM} \mathrm{HCO}-$ & $7.51 \pm 0.69$ & $1.59 \pm 0.16$ & $4.72 \pm 0.5$ & $16.82 \pm 2.97$ & $3.92 \pm 0.43$ & $9.3 \pm 0.75$ & $0.4 \pm 0.1$ & $44.19 \pm 5.42$ & $0.029 \pm 0.004$ \\
\hline $\begin{array}{l}50 \mathrm{mM} \text { ACS grade } \\
\mathrm{NaHCO}_{3}\end{array}$ & $7.78 \pm 0.46$ & $2.33 \pm 0.18$ & $2.46 \pm 0.14$ & $31.82 \pm 1.73$ & $5.61 \pm 0.35$ & $9.06 \pm 0.43$ & $0.58 \pm 0.06$ & $59.63 \pm 3.34^{*}$ & $0.061 \pm 0.008^{*}$ \\
\hline $\begin{array}{l}50 \mathrm{mM} \text { industrial } \\
\text { grade } \mathrm{NaHCO}_{3}\end{array}$ & $7.38 \pm 0.37$ & $2.11 \pm 0.05$ & $2.28 \pm 0.18$ & $30.06 \pm 1.39$ & $5.16 \pm 0.13$ & $8.43 \pm 0.74$ & $0.61 \pm 0.05$ & $56.04 \pm 2.9^{*}$ & $0.058 \pm 0.001^{*}$ \\
\hline $50 \mathrm{mM} \mathrm{KHCO}_{3}$ & $6.8 \pm 0.22$ & $1.79 \pm 0.05$ & $2.64 \pm 1.11$ & $27 \pm 2.08$ & $5.15 \pm 0.07$ & $7.74 \pm 0.3$ & $0.54 \pm 0.13$ & $51.62 \pm 2.25^{*}$ & $0.048 \pm 0.012^{*}$ \\
\hline $50 \mathrm{mM} \mathrm{Na}_{2} \mathrm{CO}_{3}$ & $5.12 \pm 0.11$ & $1.26 \pm 0.03$ & $2.56 \pm 0.04$ & $14.47 \pm 0.12$ & $3.4 \pm 0.02$ & $5.84 \pm 0.05$ & $0.2 \pm 0.05$ & $32.82 \pm 0.28$ & $0.02 \pm 0.001$ \\
\hline $\begin{array}{l}25 \mathrm{mM} \\
\mathrm{NaHCO}_{3} \cdot \mathrm{Na}_{2} \mathrm{CO}_{3}\end{array}$ & $6.69 \pm 0.08$ & $1.84 \pm 0.03$ & $3.82 \pm 0.09$ & $23 \pm 0.62$ & $4.67 \pm 0.09$ & $7.72 \pm 0.12$ & $0.47 \pm 0.08$ & $53.33 \pm 1.35^{*}$ & $0.041 \pm 0.003^{*}$ \\
\hline
\end{tabular}

Values are reported for the completion of the experiment (5.75 days) $(n=3)$. All values expressed as weight percent (\% weight FAME/weight biomass) unless indicated otherwise

${ }^{*} p$ value $<0.05$ as determined by a two-tailed $t$ test, statistically significant higher [difference between treatment and control group $\left(0\right.$ mM $\left.\mathrm{HCO}_{3}^{-}\right)$]

${ }^{a}$ Sum of other compounds detected

${ }^{\mathrm{b}}$ Total FAMEs 
bicarbonate addition affects cell division and actually decreases the number of newly produced cells during the lipid accumulation phase. Therefore, in part 2 of this study, a strategy was developed that allowed for faster biomass production through the addition of small amounts of bicarbonate during the initial culturing before lipid accumulation was triggered. Implementation of such an optimized strategy may further improve lipid productivity of algal cultures.

\section{Part 2: optimized growth and lipid accumulation}

Part 1 of this manuscript described that the lipid content (in \% lipid per biomass) can be increased through bicarbonate supplementation of $C$. vulgaris cultures. However, cell replication was largely arrested at the time of bicarbonate addition (Table 1). Based on these as well as previously reported observations [33-35], it was hypothesized that enhanced cell growth and thus higher culture productivity might be achievable by adding low concentrations of bicarbonate before inducing lipid production using a second addition of bicarbonate salt at a higher concentration near nitrogen depletion.

Industrial and laboratory systems often use $\mathrm{CO}_{2}(1-5$ $\%$ up to $100 \% v / v$ ) to control the $\mathrm{pH}$ of algal cultures between 8.0 and 8.7 [44, 46, 47]. This process can be automated via $\mathrm{pH}$ controllers, which initiate a $\mathrm{CO}_{2}$ gas sparge when the $\mathrm{pH}$ values in the culture medium reach undesirably high levels and discontinue the addition of $\mathrm{CO}_{2}$ once the $\mathrm{pH}$ has been lowered sufficiently.

In an attempt to increase biomass production prior to inducing lipid accumulation, $5 \mathrm{mM}$ ACS grade $\mathrm{NaHCO}_{3}$ (final concentration at inoculation) was added to the medium at the beginning of cultivation and a $\mathrm{pH}$ controller maintained the medium $\mathrm{pH}$ between 8.4 and 8.7 by automatically sparging the system with $5 \% \mathrm{CO}_{2}(v / v)$ when the $\mathrm{pH}$ reached 8.7 and turning off when the $\mathrm{pH}$ had declined to 8.4. These cultures were also supplemented with $50 \mathrm{mM}$ ACS grade $\mathrm{NaHCO}_{3}$ at day 4, just prior to nitrogen depletion, to induce TAG accumulation. This optimized growth and lipid accumulation strategy (optimized scenario) was compared to the following four culture conditions: (1) cultures sparged with atmospheric air only, (2) cultures sparged with atmospheric air and the medium supplemented with $5 \mathrm{mM}$ $\mathrm{NaHCO}_{3}$ prior to inoculation, (3) cultures sparged with atmospheric air and $\mathrm{pH}$ regulated with $5 \% \mathrm{CO}_{2}(v / v)$ during the daylight hours to maintain a $\mathrm{pH}$ range of 8.4-8.7, and (4) cultures aerated with $5 \% \mathrm{CO}_{2}(v / v)$ continuously during the daylight hours. In this way, each inorganic carbon regime (i.e., $5 \mathrm{mM} \mathrm{NaHCO} 3,5 \% \mathrm{CO}_{2}$, $\mathrm{pH}$ regulated, and atmospheric air only) was evaluated individually, and the optimized scenario could be compared to those individual systems. This part of the study was not intended to be a full factorial design study, but rather synthesized the knowledge of previous work (reported here and elsewhere) to devise a strategy for improved growth and lipid accumulation without the need for using high concentration and possibly high-purity sources of $\mathrm{CO}_{2}$ for algal growth and lipid accumulation.

The initial addition of $5 \mathrm{mM}$ bicarbonate increased the average specific growth rate and biomass productivity (in $\mathrm{g} \mathrm{CDW} \mathrm{L}{ }^{-1}$ day $^{-1}$ ) for the optimized scenario by 69 and $27 \%$, respectively, compared to the other treatments (Fig. 3, Table 3). Furthermore, the addition of $50 \mathrm{mM}$ bicarbonate to the optimized scenario on day 4 resulted in the expected cessation of cellular replication (Fig. 3, black arrow and Table 3) and increased lipid accumulation (discussed below) [33-35].

The total chlorophyll content of the cultures was monitored throughout the experiment to estimate the photosynthetic potential of each culture (Fig. 4). The optimized scenario exhibited an early increase in chlorophyll concentration, as compared to the other cultures, indicating a higher degree of culture health and photosynthetic potential during the exponential growth phase. Similarly, the concentration of chlorophyll was higher in the optimized scenario during the nitrogen limitation induced lipid accumulation phase (after day 4). This increased chlorophyll content along

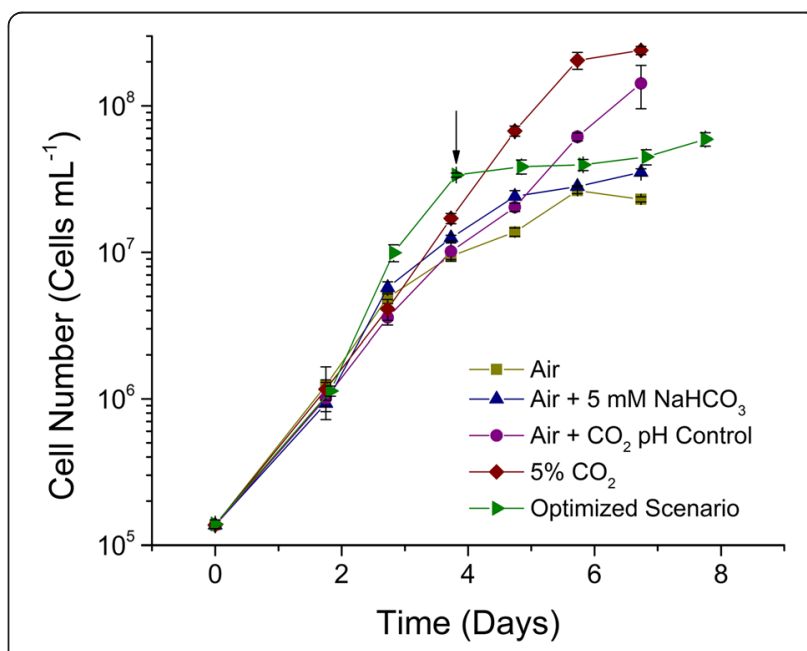

Fig. 3 Growth (cells $\mathrm{mL}^{-1}$ ) of cultures of C. vulgaris cultured under various inorganic carbon regimes. (Square) Continuous sparge of atmospheric air, (triangle) continuous sparge of atmospheric air and supplemented with $5 \mathrm{mM} \mathrm{NaHCO}_{3}$ at inoculation, (circle) continuous sparge of atmospheric air supplemented periodically with $5 \% \mathrm{CO}_{2}$ $(\mathrm{v} / \mathrm{v})$ to maintain $\mathrm{pH}$ between 8.4 and 8.7 , (diamond) continuous sparge of atmospheric air supplemented with $5 \% \mathrm{CO}_{2}(\mathrm{~V} / \mathrm{V})$ during daytime hours, and (right pointing triangle) the optimized scenario of a continuous sparge of atmospheric air supplemented periodically with $5 \% \mathrm{CO}_{2}(\mathrm{~V} / \mathrm{V})$ to maintain $\mathrm{pH}$ between 8.4 and 8.7 and an initial addition of $5 \mathrm{mM} \mathrm{NaHCO}_{3}$ at inoculation plus an additional 50 $\mathrm{mM} \mathrm{NaHCO}$ just prior to nitrogen depletion to stimulate TAG accumulation $(n=3)$. Arrow indicates time of $50 \mathrm{mM} \mathrm{NaHCO}_{3}$ addition just prior to nitrogen depletion of the culture medium 
Table 3 C. vulgaris culturing characteristics when grown under various inorganic carbon regimes

\begin{tabular}{|c|c|c|c|c|}
\hline Treatment & $\begin{array}{l}\text { Cell concentration } \\
\left(\times 10^{7} \text { cells } \mathrm{mL}^{-1}\right)\end{array}$ & $\begin{array}{l}\text { Specific growth rate } \\
\left(\mu_{\max } \text { day }^{-1}\right)\end{array}$ & $\begin{array}{l}\text { Biomass productivity } \\
\left(\mathrm{g} \mathrm{L}^{-1} \text { day }^{-1} ; \mathrm{DCW}\right)^{\mathrm{a}}\end{array}$ & Maximum chlorophyll $\left(\mathrm{mg} \mathrm{L}^{-1}\right)$ \\
\hline Air only & $2.31 \pm 0.09^{*}$ & $0.61 \pm 0.09^{*}$ & $0.04 \pm 0.00^{*}$ & $3.52 \pm 1.0^{*}$ \\
\hline $\mathrm{Air}+5 \mathrm{mM} \mathrm{NaHCO}_{3}$ & $3.53 \pm 0.2^{*}$ & $0.82 \pm 0.02^{*}$ & $0.06 \pm 0.01^{*}$ & $5.72 \pm 1.0^{*}$ \\
\hline Air $+5 \%(v / v) \mathrm{CO}_{2} \mathrm{pH}$ control & $14.21 \pm 4.67^{* *}$ & $0.76 \pm 0.05^{*}$ & $0.11 \pm 0.02^{*}$ & $8.01 \pm 1.23^{*}$ \\
\hline $5 \%(v / v) \mathrm{CO}_{2}$ continuous & $23.92 \pm 1.55^{* *}$ & $1.02 \pm 0.02^{*}$ & $0.11 \pm 0.01^{*}$ & $8.13 \pm 1.46^{*}$ \\
\hline Optimized scenario & $5.93 \pm 0.61^{b}$ & $1.72 \pm 0.06$ & $0.14 \pm 0.00$ & $10.7 \pm 0.84$ \\
\hline
\end{tabular}

Experimental conditions: (1) continuous sparge of atmospheric air, (2) continuous sparge of atmospheric air and supplemented with $5 \mathrm{mM} \mathrm{NaHCO}$ at inoculation, (3) continuous sparge of atmospheric air supplemented periodically with $5 \% \mathrm{CO}_{2}(\mathrm{v} / \mathrm{v})$ to maintain pH between 8.4 and 8.7, (4) continuous sparge of atmospheric air supplemented with $5 \% \mathrm{CO}_{2}(\mathrm{v} / \mathrm{v})$ during daytime hours, and (5) the optimized scenario of a continuous sparge of atmospheric air supplemented periodically with $5 \% \mathrm{CO}_{2}(\mathrm{v} / \mathrm{v})$ to maintain pH between 8.4 and 8.7 and an initial addition of $5 \mathrm{mM} \mathrm{NaHCO}_{3}$ at inoculation plus an additional $50 \mathrm{mM} \mathrm{NaHCO}$ just prior to nitrogen depletion to stimulate TAG accumulation $(n=3)$. All growth yields are calculated for the exponential growth phase (i.e., from inoculation until depletion of nitrogen)

" $p$ value $<0.05$ as determined by a two-tailed $t$ test, statistically significantly lower (difference between treatment and optimized scenario)

${ }^{* *} p$ value $<0.05$ as determined by a two-tailed $t$ test, statistically significantly higher (difference between treatment and optimized scenario)

${ }^{\mathrm{a}}$ Dry cell weight (DCW) determined gravimetrically with lyophilized biomass

$\mathrm{b}_{50 \mathrm{mM} \mathrm{NaHCO}}$ addition results in cessation of cellular division

with the higher carbon fixation rates indicates a higher photosynthetic performance of the alga when cultured under the optimized scenario; however, additional photosynthetic parameters will need to be monitored in the future to verify this interpretation.

To evaluate the extent of lipid accumulation, lipid profiles were compared for cultures sparged continuously

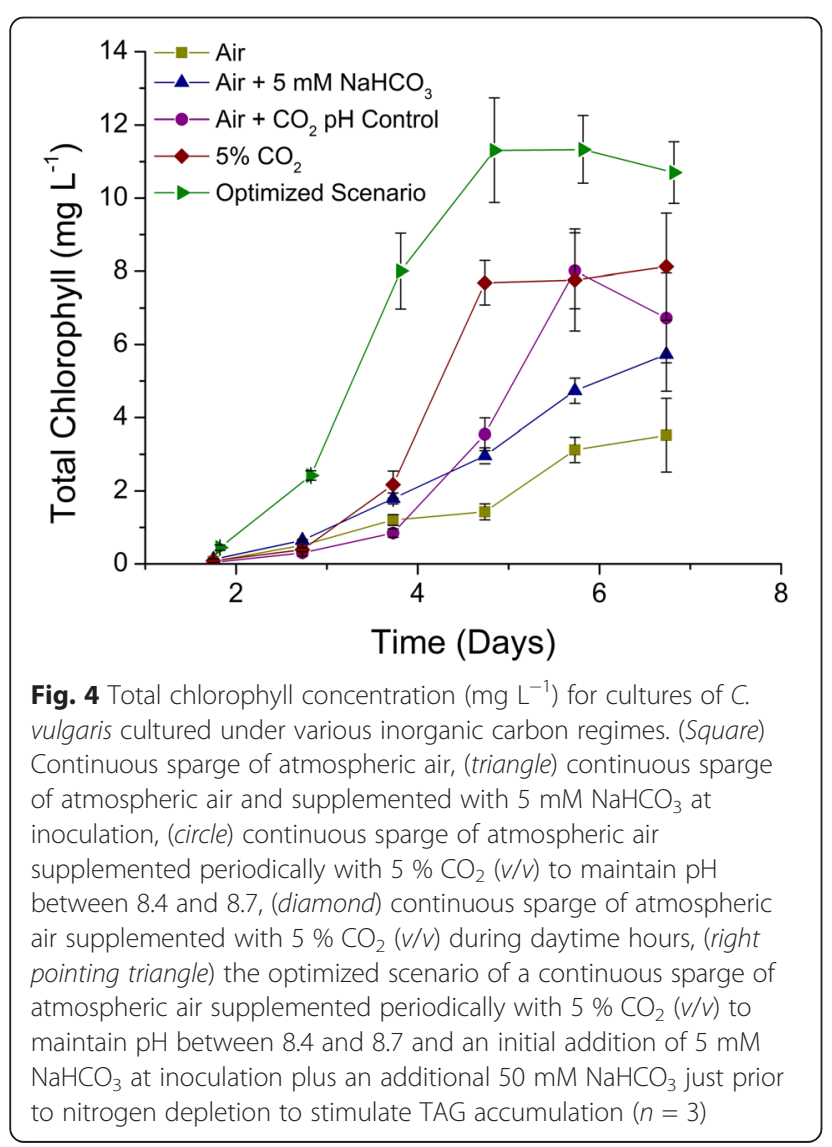

with $5 \% \mathrm{CO}_{2}$, during the daylight hours, against cultures grown under the optimized scenario (Fig. 5, Table 4). Additionally, to assess how cultures grown under the optimized scenario would perform when using a lower grade of bicarbonate, a third set of cultures was supplemented with $50 \mathrm{mM} \mathrm{NaHCO} \cdot \mathrm{Na}_{2} \mathrm{CO}_{3}$ (sesquicarbonate), instead of $50 \mathrm{mM}$ ACS grade $\mathrm{NaHCO}_{3}$, to

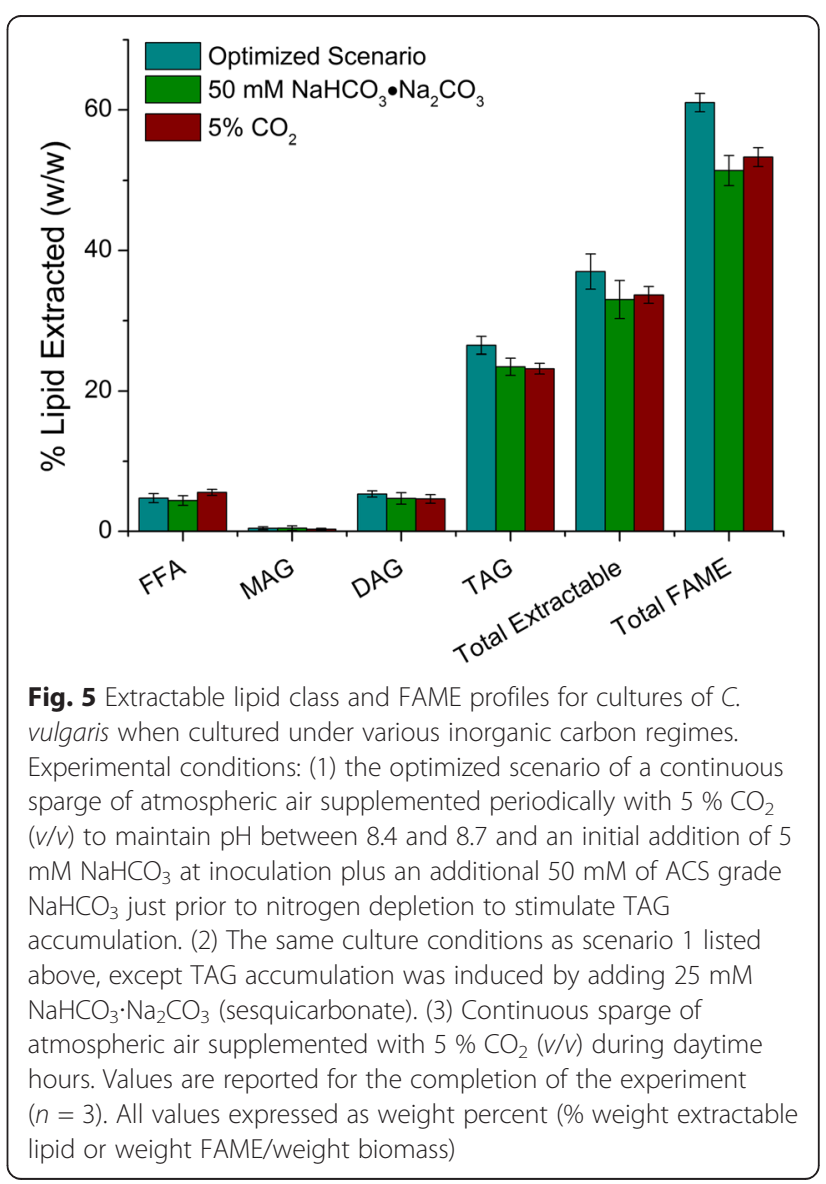


Table 4 C. vulgaris lipid characteristics for cultures grown under various inorganic carbon regimes

\begin{tabular}{|c|c|c|c|c|c|c|c|c|c|}
\hline Treatment & $\mathrm{C} 16: 0^{\mathrm{a}}$ & $\mathrm{C} 16: 1^{\mathrm{a}}$ & $\mathrm{C} 18: 0^{a}$ & $\mathrm{C} 18: 1^{\mathrm{a}}$ & $\mathrm{C} 18: 2^{\mathrm{a}}$ & $\mathrm{C} 18: 3^{\mathrm{a}}$ & Other $^{\mathrm{b}}$ & $\begin{array}{l}\text { Total biodiesel } \\
\text { potential }(\%)^{c}\end{array}$ & $\begin{array}{l}\text { Potential biodiesel } \\
\text { productivity } \\
\left(\mathrm{g} \mathrm{L}^{-1} \text { day }^{-1}\right)^{c}\end{array}$ \\
\hline $\begin{array}{l}\text { Optimized } \\
\text { Scenario }\end{array}$ & $10.66 \pm 0.3$ & $2.76 \pm 0.03$ & $5.17 \pm 0.09$ & $24.42 \pm 0.44$ & $7.17 \pm 0.14$ & $10.21 \pm 0.33$ & $0.64 \pm 0.06$ & $61.04 \pm 1.31$ & $0.098 \pm 0.002$ \\
\hline $\begin{array}{l}50 \mathrm{mM} \\
\mathrm{NaHCO}_{3} \cdot \mathrm{Na}_{2} \mathrm{CO}_{3}\end{array}$ & $9.27 \pm 0.34$ & $2.64 \pm 0.1$ & $3.97 \pm 0.11$ & $19.85 \pm 1.2$ & $6.56 \pm 0.18$ & $8.45 \pm 0.15$ & $0.68 \pm 0.09$ & $51.41 \pm 2.14^{*}$ & $0.07 \pm 0.005^{*}$ \\
\hline $\begin{array}{l}5 \%(\mathrm{~V} / \mathrm{V}) \mathrm{CO}_{2} \\
\text { Continuous }\end{array}$ & $9.45 \pm 0.7$ & $1.85 \pm 0.14$ & $2.36 \pm 0.2$ & $26.59 \pm 2.1$ & $4.58 \pm 0.4$ & $7.88 \pm 0.76$ & $0.63 \pm 0.12$ & $53.33 \pm 1.35^{*}$ & $0.091 \pm 0.005^{*}$ \\
\hline
\end{tabular}

Experimental conditions: (1) the optimized scenario of a continuous sparge of atmospheric air supplemented periodically with $5 \% \mathrm{CO}_{2}(\mathrm{v} / \mathrm{v}$ ) to maintain pH between 8.4 and 8.7 and an initial addition of $5 \mathrm{mM} \mathrm{NaHCO}_{3}$ at inoculation plus an additional $50 \mathrm{mM}$ of $\mathrm{ACS}_{\text {grade NaHCO}}$ just prior to nitrogen depletion to stimulate TAG accumulation. (2) The same culture conditions as scenario 1 listed above, except $\mathrm{TAG}$ accumulation was induced by adding 25 mM NaHCO${ }_{3} \cdot \mathrm{Na}_{2} \mathrm{CO}_{3}$ (sesquicarbonate). (3) Continuous sparge of atmospheric air supplemented with $5 \% \mathrm{CO}_{2}(v / v)$ during daytime hours ( $n=3$ ). Biodiesel productivity is calculated for the stationary growth phase (e.g., from depletion of nitrogen until termination of experiment)

${ }^{*} p$ value $<0.05$ as determined by a two-tailed $t$ test, statistically significantly lower (difference between treatment and optimized scenario)

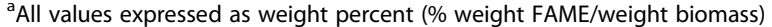

${ }^{\mathrm{b}} \mathrm{Sum}$ of other compounds detected

'Total FAMEs

induce lipid accumulation. Lipid profile data for cultures grown on only atmospheric air (with and without $5 \mathrm{mM}$ $\left.\mathrm{NaHCO}_{3}\right)$ or air with pH regulated with $5 \% \mathrm{CO}_{2}(v / v)$ have been omitted for clarity because these systems did not accumulate lipid to a larger degree than the cultures which received $5 \% \mathrm{CO}_{2}$ continuously.

Figure 5 presents extractable lipid profiles for the three treatments that accumulated significant lipids as well as total extractable lipid (sum of FFA, MAG, DAG, and TAG) and total biodiesel potential (\% FAME $w / w$ biomass). No statistical difference was observed in TAG content between cultures sparged with $5 \% \mathrm{CO}_{2}(23.2 \pm$ $0.77 \% w / w)$ and cultures supplemented with $50 \mathrm{mM}$ $\mathrm{NaHCO}_{3} \cdot \mathrm{Na}_{2} \mathrm{CO}_{3}(23.5 \pm 1.5 \% \mathrm{w} / \mathrm{w})$. Cultures supplemented with $50 \mathrm{mM}$ ACS grade $\mathrm{NaHCO}_{3}$ on day 4 (Optimized Scenario) increased in TAG content by $3.3 \%$ $(w / w)$ over the $5 \% \mathrm{CO}_{2}$ control $(t$ test $p<0.05)$. Free fatty acid, MAG and DAG contents were statistically equivalent between all three cultures. Total biodiesel potential (\% FAME biomass ${ }^{-1}$ ) was increased from $53.3 \pm$ 1.34 (\% w/w) (5 \% $\mathrm{CO}_{2}$ continuously) to $61 \pm 1.3(\% \mathrm{w} / w)$ under the optimized scenario (Fig. 5), and the averaged biodiesel productivity over the 7-day culturing time was increased by $7.7 \%$ (Table 4). The increase in total biodiesel potential is partially attributed to increased concentrations of TAG in the optimized scenario; however, a portion also appears to have been derived from membrane-bound lipids or glycolipids. Table 4 presents FAME profiles for each of the three cultures, separated by carbon chain length and saturation. As observed in the first part of this work, cells supplemented with ACS grade sodium bicarbonate accumulated slightly, yet statistically significantly $(t$ test, $p<0.05)$ more of each fatty acid (in \% weight FAME/weight biomass) except for the monounsaturated $\mathrm{C}_{18}$ FAMEs, which reached the highest concentration in cultures grown on $5 \% \mathrm{CO}_{2}$, albeit not significantly higher $(t$ test, $p=0.15)$. As discussed in part 1 , changes in lipid profiles during nitrogen starvation or bicarbonate addition have been reported previously and the observations described here largely agree with those reports $[38,39,44]$.

\section{Conclusions}

A study was conducted comparing the influence of various bicarbonate salts on growth and lipid accumulation in the model Chlorophyte Chlorella vulgaris sp. strain UTEX 395. An optimized, two-phase enhanced growth and lipid accumulation scenario was developed, which uses strategic additions of sodium bicarbonate to enhance growth rates and lipid accumulation rates in cultures of C. vulgaris, as compared to traditional growth regimes which usually supply elevated concentrations of $\mathrm{CO}_{2(\mathrm{~g})}$ as the sole inorganic carbon substrate. From an industrial perspective, the transport, storage, and delivery of gaseous $\mathrm{CO}_{2}$ has been suggested to be costly for large-scale algal production [7, 48-50]. However, competitive growth rates in microalgae cultures may only be achievable when elevated concentrations of dissolved inorganic carbon are present in the medium. By supplementing cultures with low doses of bicarbonate to first enhance the specific growth rate, and secondly by adding elevated concentrations of bicarbonate in concert with medium nitrogen depletion, both growth and lipid accumulation rates were increased for the optimized scenario by 69 and $27 \%$, respectively, above cultures which received $5 \% \mathrm{CO}_{2}$ continuously. In addition, it was found that the raw, unprocessed form of bicarbonate (sesquicarbonate) could be an adequate source of inorganic carbon for both enhanced growth and lipid accumulation in cultures of $C$. vulgaris. These data indicate that the type and strategy (e.g., timing, concentration, and purity) of inorganic carbon addition may have a significant influence on lipid production in C. vulgaris. 
In summary, the strategies presented here could contribute towards a potentially cost-competitive approach to optimizing dissolved inorganic carbon supply in algal biofuel production through alkalinity control via the strategic addition of bicarbonate salts. The feasibility of this technology might be location specific and should be assessed using a techno-economic analysis to compare costs associated with bicarbonate addition compared to gaseous $\mathrm{CO}_{2}$ addition. Beyond further optimization of inorganic carbon supply, additional optimization can perceivably be achieved via improved strain selection and optimized light parameters (i.e., photosynthetic flux available to the algae due to culture density). Much of this work is in progress in our laboratories and elsewhere.

\section{Methods}

\section{Strain and culturing conditions}

Chlorella vulgaris sp. strain UTEX 395 (University of Texas at Austin) was cultured on Bold's basal medium [51] with $\mathrm{pH}$ adjusted to 8.7 prior to autoclaving. Cultures were either grown in batch airlift tube reactors or baffled flasks, depending on the experimental conditions, as outlined below.

\section{Part 1: bicarbonate salt study}

Cultures of C. vulgaris were grown in $100 \mathrm{~mL}$ of medium in a $250-\mathrm{mL}$ baffled shaker flask (Fisher Scientific, Palatine, IL) until just prior to medium nitrogen depletion. Temperature was maintained at $24{ }^{\circ} \mathrm{C} \pm 1{ }^{\circ} \mathrm{C}$. Light (200 $\mu \mathrm{mol}$ photons $\mathrm{m}^{-2} \mathrm{~s}^{-1}$ ) was maintained on a 14:10 L/D cycle using a light incubator (Percival Scientific, Inc., Perry, IA). The biomass was concentrated via centrifugation at $4800 \times g$ and $4{ }^{\circ} \mathrm{C}$ for $10 \mathrm{~min}$ (Thermo Scientific, Sorvall Legend XTR, Waltham, MA). Biomass pellets were re-suspended in $100 \mathrm{~mL}$ of Bold's basal medium depleted of nitrogen and amended with one of the following bicarbonate salts (final concentrations): $0 \mathrm{mM}$ $\mathrm{HCO}_{3}^{-}$(control), $50 \mathrm{mM}$ ACS grade $\mathrm{NaHCO}_{3}, 50 \mathrm{mM}$ ACS grade $\mathrm{Na}_{2} \mathrm{CO}_{3}$ (both from Sigma-Aldrich, St. Louis $\mathrm{MO}$ ), $50 \mathrm{mM}$ industrial grade $\mathrm{NaHCO}_{3}, 50 \mathrm{mM}$ $\mathrm{NH}_{4} \mathrm{HCO}_{3}, 50 \mathrm{mM} \mathrm{KHCO}$, and $25 \mathrm{mM}$ natural grade $\mathrm{NaHCO}_{3} \cdot \mathrm{Na}_{2} \mathrm{CO}_{3}$ (sesquicarbonate) (all from Church \& Dwight Co., Inc.; Princeton, NJ). All studies were conducted in triplicate.

\section{Part 2: inorganic carbon growth and lipid accumulation study}

Experiments were conducted in triplicate batch cultures using $70 \times 500 \mathrm{~mm}$ glass tubes containing $1.2 \mathrm{~L}$ medium submersed in a water bath to control temperature at $24{ }^{\circ} \mathrm{C} \pm 1{ }^{\circ} \mathrm{C}$. Rubber stoppers, containing ports for aeration and sampling, were used to seal the tubes. Light $\left(400 \mu \mathrm{mol}\right.$ photons $\left.\mathrm{m}^{-2} \mathrm{~s}^{-1}\right)$ was maintained on a 14:10 L/D cycle using a light bank containing T5 fluorescent tubes. Aeration $\left(400 \mathrm{~mL} \mathrm{~min}{ }^{-1}\right)$ was supplied by humidified compressed air (supplemented with $5 \% \mathrm{CO}_{2}(v / v)$ for high $\mathrm{CO}_{2}$ or $\mathrm{pH}$-controlled conditions during daylight hours) and controlled using individual rotameters for each bioreactor (Cole-Parmer, USA). ACS grade sodium bicarbonate was used in all experiments involving bicarbonate addition (Sigma-Aldrich, St. Louis MO), and natural grade $\mathrm{NaHCO}_{3} \cdot \mathrm{Na}_{2} \mathrm{CO}_{3}$ (Church \& Dwight, Princeton, NJ) was used in all experiments involving sesquicarbonate.

\section{Culture analysis}

Cultures were checked for bacterial contamination by streaking culture subsamples onto Bold's basal medium agar supplemented with $0.05 \%$ yeast extract and $0.05 \%$ glucose. No growth of colonies was detected after 7 days of incubation at room temperature in the dark. Cell concentrations were determined using an optical hemacytometer with a minimum of 400 cells counted per sample for statistical reliability. Dry cell weights (DCWs) were determined by transferring $50 \mathrm{~mL}$ of culture into a preweighed $50 \mathrm{~mL}$ centrifuge tube (Fisher Scientific, Palatine, IL), followed by centrifugation at $4800 \times g$ at $4{ }^{\circ} \mathrm{C}$ for 10 min (Thermo Scientific, Sorvall Legend XTR, Waltham, $\mathrm{MA})$. The concentrated biomass was rinsed with deionized $\mathrm{H}_{2} \mathrm{O}\left(\mathrm{diH}_{2} \mathrm{O}\right), 18 \mathrm{M} \Omega$, to remove media salts and excess bicarbonate, before centrifuging again. Remaining algal pellets were frozen and lyophilized (Labconco lyophilizer, Kansas City, MO) for 48 h. DCWs were calculated by subtracting the weight of the biomass-free centrifuge tube from the weight of the centrifuge tube with lyophilized biomass.

\section{Analysis of media components}

Medium $\mathrm{pH}$ was measured using a standard bench top $\mathrm{pH}$ meter. Nitrate concentrations were measured using ion chromatography (Dionex, Sunnyvale, CA), respectively, using previously described protocols [34].

\section{Dissolved inorganic carbon analysis}

Dissolved inorganic carbon (DIC, sum of dissolved carbon dioxide, bicarbonate, and carbonate) in the medium was measured using previously described protocols [34]. Briefly, $8 \mathrm{~mL}$ of culture were filtered, $0.2 \mu \mathrm{m}$ pore size, and the supernatant was analyzed with a Skalar Formacs TOC/TN analyzer using a Skalar LAS-160 autosampler. DIC concentrations were quantified by correlating peak area to a standard curve constructed from bicarbonate and carbonate mixtures (Sigma-Aldrich).

\section{Chlorophyll measurements}

Chlorophylls a and b, and carotenoids were determined using the methanol extraction and optical absorption correlation described in [52]. Of the culture, $1 \mathrm{~mL}$ was 
centrifuged at $16,000 \times g$ for $5 \mathrm{~min}$, after which the supernatant was discarded. Methanol, $1 \mathrm{~mL}$, was added to the pellet, and the tube was vortexed and lightly sonicated to disperse the pellet. The suspension was heated at $70{ }^{\circ} \mathrm{C}$ for $5 \mathrm{~min}$ in a water bath followed by centrifugation at $16,000 \times g$ for $3 \mathrm{~min}$. Absorption was read at 666, 653, and $470 \mathrm{~nm}$. Calculations for chlorophyll and carotenoids $\left(\mu \mathrm{g} \mathrm{mL} L^{-1}\right)$ were conducted as previously described in [52].

\section{Harvesting}

Cultures were harvested just prior to medium nitrogen depletion and at the conclusion of each experiment. Each time, two aliquots of $50 \mathrm{~mL}$ were dispensed into 50-mL centrifuge tubes (Fisher Scientific, Palatine, IL) and centrifuged (Thermo Scientific, Sorvall Legend XTR, Waltham, MA) at $4800 \times g$ at $4{ }^{\circ} \mathrm{C}$ for $10 \mathrm{~min}$. The concentrated biomass was rinsed with $\mathrm{diH}_{2} \mathrm{O}$ to remove media salts and excess bicarbonate, before centrifuging again. The remaining algal pellets were rapidly frozen and lyophilized (Labconco lyophilizer, Kansas City, MO) for $48 \mathrm{~h}$ and stored at $-20{ }^{\circ} \mathrm{C}$ for subsequent lipid analysis.

\section{Extraction of lipids from dry biomass using bead beating}

Extraction and analysis of extractable lipids were conducted as previously reported [39]. Approximately $30 \mathrm{mg}$ of dried biomass was combined with $1 \mathrm{~mL}$ of chloroform in a $1.5-\mathrm{mL}$ stainless steel microvial with a silicone cap (BioSpec Products, Bartlesville, OK). Three types of beads $(0.6 \mathrm{~g}$ of $0.1 \mathrm{~mm}$ zirconium/silica beads, $0.4 \mathrm{~g}$ of $1.0 \mathrm{~mm}$ glass beads, two $2.7 \mathrm{~mm}$ glass beads) were added to each vial before capping. A FastPrep bead beater (Bio101/ Thermo Savant, Carlsbad, CA) was used to agitate the vials for six $20 \mathrm{~s}$ pulses at power level 6.5 followed by a 1 min cool down period between pulses. Total bead beating time was $2 \mathrm{~min}$. The mixture of solvent, residual biomass, and beads was then transferred to a 15-mL Pyrex test tube with a Teflon-lined screw cap (Kimble-Chase, Vineland, $\mathrm{NJ}$ ), and the steel microvial was rinsed twice with $1 \mathrm{~mL}$ of chloroform, which was also added to the test tube, bringing the total solvent volume to $3 \mathrm{~mL}$. Of $15 \% \mathrm{NaCl}(v / v)$, $1 \mathrm{~mL}$ was added to enhance phase separation. Samples were then centrifuged at $1200 \times g$ for 2 min to separate the residual biomass. Of the organic phase, $1 \mathrm{~mL}$ was removed from the bottom of the test tube using a glass syringe and transferred to a $2-\mathrm{mL}$ GC vial for GC-FID analysis.

\section{Transesterification for FAME analysis}

Transesterification of fatty acids was conducted using a previously described protocol [53] with modifications. FAME composition was analyzed using gas chromatography-mass spectroscopy (GC-MS) detection.
Briefly, approximately $20 \mathrm{mg}$ of dried algal biomass was transferred to a $15-\mathrm{mL}$ Pyrex test tube with a Teflonlined screw cap (Kimble-Chase, Vineland, NJ). Toluene, $1 \mathrm{~mL}$, and sodium methoxide, $2 \mathrm{~mL}$ (Fisher Scientific, Pittsburgh PA), were added to each test tube along with $10 \mu \mathrm{L}$ of a $10 \mathrm{mg} \mathrm{mL}^{-1}$ standard mixture (C11:0 and C17:0 TAG) to monitor transesterification efficiency of the TAG into FAME. Samples were heated in an oven for $30 \mathrm{~min}$ at $90^{\circ} \mathrm{C}$ and vortexed every $10 \mathrm{~min}$. Samples were allowed to cool to room temperature before $2 \mathrm{~mL}$ of $14 \%$ boron tri-fluoride in methanol (Sigma-Aldrich, St. Louis, MO) were added and samples were heated again for an additional $30 \mathrm{~min}$. Samples were again allowed to cool before $10 \mu \mathrm{L}$ of a $10 \mathrm{mg} \mathrm{mL}^{-1}$ of C23:0 FAME was added to assess the completeness of partitioning FAME into the organic phase. Additionally, 0.8 $\mathrm{mL}$ of hexane and $0.8 \mathrm{~mL}$ of a saturated salt water solution $\left(\mathrm{NaCl}\right.$ in $\left.\operatorname{diH}_{2} \mathrm{O}\right)$ were added. Samples were heated for $10 \mathrm{~min}$ at $90{ }^{\circ} \mathrm{C}$ to facilitate FAME partitioning into the organic phase, vortexed for $10 \mathrm{~s}$ and centrifuged at $1200 \times g$ for $2 \mathrm{~min}$ to enhance phase separation. Of the organic phase, $1 \mathrm{~mL}$ was removed from the top layer using a glass syringe and transferred to a $2-\mathrm{mL} \mathrm{GC}$ vial for GC-MS analysis.

\section{Lipid analysis \\ GC-FID}

GC-FID analysis was performed according to a previously published protocol [39]. Briefly, a $1-\mu \mathrm{L}$ splitless injection was performed using an autosampler into a GC-FID (Agilent 6890 N, Santa Clara CA) equipped with a 15-m (fused silica) RTX biodiesel column (Restek, Bellefonte PA). The initial column temperature was held at $100{ }^{\circ} \mathrm{C}$ for $1 \mathrm{~min}$, before being increased to $370{ }^{\circ} \mathrm{C}$ at a rate of $10^{\circ} \mathrm{C} \mathrm{min}^{-1}$. The injector temperature was held constant at $320{ }^{\circ} \mathrm{C}$. Helium was used as the carrier gas and column flow was held at $1.3 \mathrm{~mL} \mathrm{~min}^{-1}$ for $22 \mathrm{~min}$, increased to $1.5 \mathrm{~mL} \mathrm{~min}^{-1}$, held for $2 \mathrm{~min}$, increased to $1.7 \mathrm{~mL} \mathrm{~min}{ }^{-1}$, and held for $12 \mathrm{~min}$. All flow rate in-

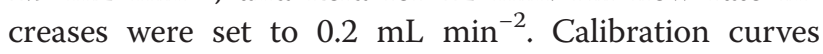
were constructed for each of the following standards: C12:0, C14:0, C16:0, C18:0, and C20:0 FFAs; C12:0, C14:0, C16:0, and C18:0 MAGs; C12:0, C14:0, C16:0, and C18:0 DAGs; along with C11:0, C12:0, C14:0, C16:0, C17:0, C18:0, and C20:0 TAGs (Sigma-Aldrich, St. Louis MO) for quantification $\left(r^{2}>0.99\right)$. This GC method allows for an estimate of the amounts of FFA, MAG, DAG, and TAGs in a single analysis as detailed in [39].

\section{GC-MS}

GC-MS analysis was performed as follows. Briefly, $1-\mu \mathrm{L}$ split (2:1) injections were performed using an autosampler into a GC-MS (Agilent 6890 N GC and Agilent 5973 Networked MS) equipped with a $60 \mathrm{~m} \times 0.25 \mathrm{~mm} \times 0.15 \mathrm{~mm}$ 
Agilent DB-23 column (0.25 $\mu \mathrm{m}$ phase thickness). The injector temperature was $280{ }^{\circ} \mathrm{C}$, and the detector temperature was $150{ }^{\circ} \mathrm{C}$. The initial column temperature was $50{ }^{\circ} \mathrm{C}$ (held for $1 \mathrm{~min}$ ) and was increased to $175{ }^{\circ} \mathrm{C}$ at a rate of $25{ }^{\circ} \mathrm{C} \mathrm{min}{ }^{-1}$, immediately followed by a ramp at $4{ }^{\circ} \mathrm{C} \min ^{-1}$ to a final temperature of $230{ }^{\circ} \mathrm{C}$ which was held for $10 \mathrm{~min}$ before run termination. Helium was used as the carrier gas and

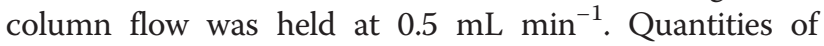
FAMEs were determined by quantifying each response peak with the nearest eluting calibration standard based on retention time, using MSD ChemStation software (Ver. D.02.00.275), with additional analyses performed using a custom program described below. A 28component fatty acid methyl ester standard prepared in methylene chloride (NLEA FAME mixture; Restek, Bellefonte, PA) was used for GC-MS retention time identification and response curve generation $\left(r^{2}>0.99\right)$.

\section{Lipid quantification and analysis}

Lipid quantification was performed using a custom program developed specifically for this purpose [39]. Chromatogram data from the GC-FID and GC-MS were exported from the instrument software (Chemstation Ver. B.02.01-SR1) as a Microsoft Excel spreadsheet. The spreadsheet was then imported into a web-based software application written in Microsoft's ASP.NET framework using C\# and MVC as the coding language and paradigm, respectively. Data were stored with unique identifiers in a Microsoft SQL database. Six-point calibration curves were constructed using the LINEST function which is built into the ASP.NET framework library. Chromatogram peaks were quantified based on the closest standard, as determined by retention time of the sample peak and standard peak, respectively. All chromatograms were manually integrated and inspected prior to export to ensure accuracy and reliability. Manual calculations were performed periodically using Excel to verify software results. Lipid extraction and analysis techniques used for this work have consistently found the analytical error to be within $\pm 1-3 \%[39,54]$.

\section{Calculations}

Specific growth rates were calculated using the following equation:

$$
\mu=\ln \left(\frac{\mathrm{mt} 2}{\mathrm{mt} 1}\right) /(t 2-t 1) t 2>t 1
$$

Productivity was calculated using the following equation:

$$
p=(\mathrm{mt} 2-\mathrm{mt} 1) /(t 2-t 1) t 2>t 1
$$

where $\mathrm{mt} 1$ and $\mathrm{mt} 2$ are the biomass concentrations at the different time points ( $t 1$ and $t 2)$, respectively.

\section{Additional file}

Additional file 1: Cell concentration of cultures of $C$. vulgaris cultured under various inorganic carbon regimes. Description of data: final cell concentrations observed in cultures with different bicarbonate salts: (ש) $0 \mathrm{mM} \mathrm{HCO}_{3}^{-}$(control), (•) $50 \mathrm{mM} \mathrm{ACS}$ grade $\mathrm{NaHCO}_{3}$ (grade 1),

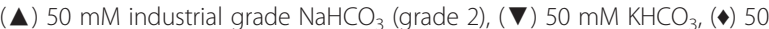
$\mathrm{mM} \mathrm{NH}_{4} \mathrm{HCO}_{3}$, ( $50 \mathrm{mM} \mathrm{Na}_{2} \mathrm{CO}_{3}$, and $(\backslash) 25 \mathrm{mM} \mathrm{NaHCO} \cdot \mathrm{Na}_{2} \mathrm{CO}_{3}(25$ $\mathrm{mM}$ of sesquicarbonate was used to provide equimolar carbon) $(n=3)$.

\section{Abbreviations}

FFA: free fatty acid; MAG: monoacylglyceride; DAG: diacylglyceride; TAG: triacylglyceride; FAME: fatty acid methyl ester; DIC: dissolved inorganic carbon; GC-FID: gas chromatography-flame ionization detection; GC-MS: gas chromatography-mass spectroscopy; Chl a: chlorophyll a; Chl b: chlorophyll b; CCM: carbon concentrating mechanism; RuBisCO: ribulose-1,5-bisphospate carboxylase oxygenase; ACS: American Chemical Society; DCW: dry cell weight; ppm: parts per million; TOC/TN: total organic carbon/total nitrogen; L/D cycle: light/dark cycle.

\section{Competing interests}

A patent application entitled "Bicarbonate Trigger for Inducing Lipid Accumulation in Algal Systems" was filed by Keith Cooksey, Robert Gardner, and Brent Peyton. The other authors declare that they have no competing interests.

\section{Authors' contributions}

EL carried out growth and biomass harvest assays, conducted lipid extraction and analysis, and drafted the manuscript. TP and RDG carried out DIC, pH, chlorophyll, and nutrient assays and participated in study design, study coordination, data analysis/interpretation, and drafting the manuscript. KEC, $\mathrm{BP}$, and RG participated in the study design, study coordination, data analysis/interpretation, and manuscript preparation. All authors read and approved the final manuscript.

\section{Acknowledgements}

The authors would like to thank all members of the MSU Algal Biofuels Group for their thoughtful discussions. This material is based upon work supported by the National Science Foundation (NSF) under CHE-1230632. A portion of this research was supported by the U.S. Department of Energy (DOE) Office of Energy Efficiency and Renewable Energy (EERE) Biomass Program under Contract No. DE-EE0005993. Partial support for EL and RDG was also provided by the NSF IGERT Program in Geobiological Systems (DGE 0654336). Support for RDG \& EL was also provided by Church \& Dwight Co., Inc. Instrumental support was provided through the Center for Biofilm Engineering (CBE) at Montana State University (MSU) as well as by the Environmental and Biofilm Mass Spectrometry Facility (EBMSF) funded through DURIP Contract Number: W911NF0510255 and the MSU Thermal Biology Institute from the NASA Exobiology Program Project NAG5-8807.

\section{Author details}

${ }^{1}$ Center for Biofilm Engineering and Department of Chemical and Biological Engineering, Montana State University, Bozeman, MT 59717, USA. ${ }^{2}$ Department of Bioproducts and Biosystems Engineering and West Central Research and Outreach Center, University of Minnesota, St. Paul, MN 55108, USA. ${ }^{3}$ Environmental Biotechnology Consultants, Manhattan, MT 59741, USA.

Received: 22 October 2014 Accepted: 26 May 2015

Published online: 11 June 2015

\section{References}

1. Dismukes GC, Carrieri D, Bennette N, Ananyev GM, Posewitz MC. Aquatic phototrophs: Efficient alternatives to land-based crops for biofuels. Curr Opin Biotechnol. 2008;19:235-40.

2. How dependent are we on foreign oil? [http://www.eia.gov/ energy_in_brief/foreign_oil_dependence.cfm]

3. National Research Council: Advancing the Science of Climate Change. Washington, DC, USA; 2010.

4. Stocker TFD, Qin G-K, Plattner M, Tignor SK, Allen J, Boschung A, et al. Climate Change 2013: The Physical Science Basis. Cambridge: Contribution 
of Working Group I to the Fifth Assessment Report of the Intergovernmental Panel on Climate Change; 2013.

5. Dukes JS. Burning buried sunshine: Human consumption of ancient solar energy. Clim Chang. 2003;61:31-44.

6. US Department of Energy: National Algal Biofuels Technology Roadmap. 2010(May).

7. Yang J, Xu M, Zhang X, Hu Q, Sommerfeld M, Chen Y. Life-cycle analysis on biodiesel production from microalgae: Water footprint and nutrients balance. Bioresour Technol. 2011;102:159-65.

8. Hu Q, Sommerfeld M, Jarvis E, Ghirardi M, Posewitz M, Seibert M, et al. Microalgal triacylglycerols as feedstocks for biofuel production: Perspectives and advances. Plant J. 2008;54:621-39.

9. Sheehan J: A look back at the U.S. Department of Energy's Aquatic Species Program: Biodiesel from algae. US Dep Energy's Off Fuels Dev 1998.

10. Chisti Y. Biodiesel from microalgae beats bioethanol. Trends Biotechnol. 2008:26:126-31.

11. Collet P, Hélias A, Lardon L, Ras M, Goy R-A, Steyer J-P. Life-cycle assessment of microalgae culture coupled to biogas production. Bioresour Technol. 2011;102:207-14

12. Cooney MJ, Young G, Pate R. Bio-oil from photosynthetic microalgae: Case study. Bioresour Technol. 2011;102:166-77.

13. Milne JL, Cameron JC, Page LE, Benson SM, Pakrasi HB: Algal technologies for biological capture and utilization of $\mathrm{CO}_{2}$ require breakthroughs in basic research. In Perspectives on Biofuels: Potential Benefits and Possible Pitfalls. Volume 1116. American Chemical Society; 2012:107-41 SE - 7. [ACS Symposium Series]

14. Pate R, Klise G, Wu B. Resource demand implications for US algae biofuels production scale-up. Appl Energy. 2011;88:3377-88.

15. Moroney JV, Ynalvez RA. Proposed carbon dioxide concentrating mechanism in Chlamydomonas reinhardtii. Eukaryot Cell. 2007;6:1251-9.

16. Benemann JR, Tillett DM. Utilization of carbon dioxide from fossil fuel-burning power plants with biological systems. Energy Convers Manag. 1993;34:999-1004.

17. Danckwerts PV, Kennedy AM. The kinetics of absorption of carbon dioxide into neutral and alkaline solutions. Chem Eng Sci. 1958;8:201-15.

18. Putt R, Singh M, Chinnasamy S, Das KC. An efficient system for carbonation of high-rate algae pond water to enhance $\mathrm{CO}_{2}$ mass transfer. Bioresour Technol. 2011;102:3240-5.

19. Keren N, Nedbal L, Kaplan A, Cervený J. Experimental validation of a nonequilibrium model of $\mathrm{CO}_{2}$ fluxes between gas, liquid medium, and algae in a flat-panel photobioreactor. J Ind Microbiol Biotechnol. 2010;37:1319-26

20. Grima EM, Sanchez JAP, Camacho FG, Medina AR. Gas-liquid transfer of atmospheric $\mathrm{CO}_{2}$, in micro algal cultures. J Chem Technol Biotechnol. 1993;56:329-37.

21. Stumm W, Morgan JJ. Aquatic Chemistry: Chemical Equilibria and Rates in Natural Waters. 3rd ed. New York: Wiley; 1996.

22. Raven J. Inorganic carbon acquisition by eukaryotic algae: Four current questions. Photosynth Res. 2010;106:123-34.

23. Giordano $\mathrm{M}$, Beardall J, Raven JA. $\mathrm{CO}_{2}$ concentrating mechanisms in algae: Mechanisms, environmental modulation, and evolution. Annu Rev Plant Biol. 2005;56:99-131.

24. Chi Z, Xie Y, Elloy F, Zheng Y, Hu Y, Chen S. Bicarbonate-based integrated carbon capture and algae production system with alkalihalophilic cyanobacterium. Bioresour Technol. 2013;133:513-21.

25. Thielmann J, Tolbert NE, Goyal A, Senger H. Two systems for concentrating $\mathrm{CO}_{2}$ and bicarbonate during photosynthesis by Scenedesmus. Plant Physiol. 1990;92:622-9.

26. Reinfelder JR. Carbon concentrating mechanisms in eukaryotic marine phytoplankton. Ann Rev Mar Sci. 2011;3:291-315.

27. Bozzo GG, Colman B, Matsuda Y. Active transport of $\mathrm{CO}_{2}$ and bicarbonate is induced in response to external $\mathrm{CO}_{2}$ concentration in the green alga Chlorella kessleri. J Exp Bot. 2000;51:1341-8.

28. Matsuda $\mathrm{Y}$, Colman B. Induction of $\mathrm{CO}_{2}$ and bicarbonate transport in the green alga Chlorella ellipsoidea (I. Time course of induction of the two systems). Plant Physiol. 1991;108:247-52.

29. Hopkinson BM, Dupont CL, Allen AE, Morel FMM. Efficiency of the $\mathrm{CO}_{2}$ concentrating mechanism of diatoms. Proc Natl Acad Sci U S A. 2011;108:3830-7.

30. Coleman JR, Colman B. Inorganic carbon accumulation and photosynthesis in a blue-green alga as a function of external pH. Plant Physiol. 1981;67:917-21.
31. Radmer R, Ollinger O. Light-driven uptake of oxygen, carbon dioxide, and bicarbonate by the green alga Scenedesmus. Plant Physiol. 1980;65:723-9.

32. Talbot $\mathrm{P}$, Gortares MP, Lencki RW, de la Noüe J. Absorption of $\mathrm{CO}_{2}$ in algal mass culture systems: a different characterization approach. Biotechnol Bioeng. 1991;37:834-42.

33. Gardner RD, Cooksey KE, Mus F, Macur R, Moll K, Eustance E, et al. Use of sodium bicarbonate to stimulate triacylglycerol accumulation in the chlorophyte Scenedesmus sp. and the diatom Phaeodactylum tricornutum. J Appl Phycol. 2012;24:1311-20.

34. Gardner RD, Lohman E, Gerlach R, Cooksey KE, Peyton BM. Comparison of $\mathrm{CO}_{2}$ and bicarbonate as inorganic carbon sources for triacylglycerol and starch accumulation in Chlamydomonas reinhardtii. Biotechnol Bioeng. 2013;110:87-96.

35. White DA, Pagarette A, Rooks P, Ali ST. The effect of sodium bicarbonate supplementation on growth and biochemical composition of marine microalgae cultures. J Appl Phycol. 2013;25:153-65.

36. Peng X, Liu S, Zhang W, Zhao Y, Chen L, Wang H, et al. Triacylglycerol accumulation of Phaeodactylum tricornutum with different supply of inorganic carbon. J Appl Phycol. 2013;26:131-39.

37. Guihéneuf F, Stengel DB. LC-PUFA-enriched oil production by microalgae: Accumulation of lipid and triacylglycerols containing n-3 LC-PUFA is triggered by nitrogen limitation and inorganic carbon availability in the marine haptophyte Pavlova lutheri. Mar Drugs. 2013;11:4246-66.

38. Guckert JB, Cooksey KE. Triglyceride accumulation and fatty acid profile changes in Chlorella (Chlorophyta) during high pH-induced cell inhibition. J Phycol. 1990;26:72-9.

39. Lohman E, Gardner RD, Halverson L, Macur R, Peyton BM, Gerlach R. An efficient and scalable extraction and quantification method for algal derived biofuel. J Microbiol Methods. 2013:94:235-44.

40. Wahlen BD, Willis RM, Seefeldt LC. Biodiesel production by simultaneous extraction and conversion of total lipids from microalgae, cyanobacteria, and wild mixed-cultures. Bioresour Technol. 2011:102:2724-30

41. Gardner RD, Lohman EJ, Cooksey KE, Gerlach R, Peyton BM. Cellular cycling, carbon utilization, and photosynthetic oxygen production during bicarbonate-induced triacylglycerol accumulation in Scenedesmus sp. Energies. 2013;6:6060-76.

42. Azov Y, Goldman JC. Free ammonia inhibition of algal photosynthesis in intensive cultures. Appl Environ Microbiol. 1982;43:735-9.

43. Eustance E, Gardner RD, Moll K, Menicucci J, Gerlach R, Peyton BM. Growth nitrogen utilization and biodiesel potential for two chlorophytes grown on ammonium or nitrate. J Appl Phycol. 2013;25:1663-77.

44. Laurens L, Quinn M, Van Wychen S, Templeton DW, Wolfrum EJ. Accurate and reliable quantification of total microalgal fuel potential as fatty acid methyl esters by in situ transesterification. Anal Bioanal Chem. 2012;403:167-78.

45. Guarnieri MT, Nag A, Smolinski SL, Darzins A, Seibert M, Pienkos PT. Examination of triacylglycerol biosynthetic pathways via de novo transcriptomic and proteomic analyses in an unsequenced microalga. PLoS One. 2011;6, e25851.

46. Concas A, Lutzu GA, Pisu M, Cao G. Experimental analysis and novel modeling of semi-batch photobioreactors operated with Chlorella vulgaris and fed with 100\% (V/V) CO $\mathrm{CO}_{2}$. Chem Eng J. 2012;213:203-13.

47. De Morais MG, Costa JAV. Carbon dioxide fixation by Chlorella kessleri, C. vulgaris, Scenedesmus obliquus and Spirulina sp. cultivated in flasks and vertical tubular photobioreactors. Biotechnol Lett. 2007;29:1349-52.

48. Jorquera O, Kiperstok A, Sales EA, Embiruçu M, Ghirardi ML. Comparative energy life-cycle analyses of microalgal biomass production in open ponds and photobioreactors. Bioresour Technol. 2010;101:1406-13.

49. Campbell PK, Beer T, Batten D. Life cycle assessment of biodiesel production from microalgae in ponds. Bioresour Technol. 2011;102:50-6.

50. Liu X, Saydah B, Eranki P, Colosi LM, Mitchell BG, Rhodes J, et al. Pilot-scale data provide enhanced estimates of the life cycle energy and emissions profile of algae biofuels produced via hydrothermal liquefaction. Bioresour Technol. 2013;148:163-71.

51. Nichols H, Bold H. Trichosarcina polymorpha Gen. et Sp. Nov. J Phycol. 1965;1:34-8.

52. Ördög V, Stirk WA, Bálint P, van Staden J, Lovász C. Changes in lipid, protein and pigment concentrations in nitrogen-stressed Chlorella minutissima cultures. J Appl Phycol. 2011;24:907-14. 
53. Griffiths MJ, van Hille RP, Harrison STL. Selection of direct transesterification as the preferred method for assay of fatty acid content of microalgae. Lipids. 2010;45:1053-60.

54. Lohman EJ, Gardner RD, Halverson L, Peyton BM, Gerlach R. Carbon partitioning in lipids synthesized by Chlamydomonas reinhardtii when cultured under three unique inorganic carbon regimes. Algal Res. 2014;5:171-80.

Submit your next manuscript to BioMed Central and take full advantage of:

- Convenient online submission

- Thorough peer review

- No space constraints or color figure charges

- Immediate publication on acceptance

- Inclusion in PubMed, CAS, Scopus and Google Scholar

- Research which is freely available for redistribution 